This item was submitted to Loughborough's Research Repository by the author.

Items in Figshare are protected by copyright, with all rights reserved, unless otherwise indicated.

\title{
Dispersion of fine powders in liquids
}

PLEASE CITE THE PUBLISHED VERSION

https://www.formulation.org.uk/partliq-home.html

PUBLISHER

Royal Society of Chemistry

VERSION

AM (Accepted Manuscript)

LICENCE

CC BY-NC-ND 4.0

REPOSITORY RECORD

Ozcan-Taskin, Gul. 2020. "Dispersion of Fine Powders in Liquids". Loughborough University. https://hdl.handle.net/2134/14068619.v1. 


\title{
Dispersion of Fine Powders in Liquids
}

\author{
N. G. Özcan-Taşkın \\ Loughborough University, School of Chemical Engineering, Loughborough Leicestershire LE11 3TU UK \\ N.Ozcan-Taskin@lboro.ac.uk
}

The formulation and hence manufacturing processes of several products- from pharmaceuticals to personal care, paints and inks to cosmetics, food to minerals and water treatment- require the incorporation of powders into liquids. In addition, the recent decades have seen the development of several novel, high performance products with nanoparticles in their formulation. Large scale manufacture of these to enable market introduction has often been a challenging task for process engineers and scientists.

Fine powders tend to form large clusters that float at the liquid surface due to apparent low density resulting from air entrapped within the agglomerates; poor wettability can also play a role ${ }^{(1)}$. Following on from the incorporation of the powder into the liquid, deagglomeration is required to achieve as fine a dispersion as possible. This talk will briefly go through powder incorporation highlighting some recent advances and continue with findings relating to deagglomeration. A few brief comments will be added on the delamination of nanoclays. Outlines of a few case studies will also be presented.

Powder incorporation can be performed using a stirred tank which may also act as the feed tank for a more energy intensive device used to achieve deagglomeration. In addition to conventional impellers, proprietary design batch rotor-stators ${ }^{(2)}$ or in-line rotor-stators ${ }^{(3)}$ can also be used for the purpose. These allow the introduction of the powder into the regions of high liquid velocities and have been shown to be advantageous for formulations that have a powder concentration greater than a few $\%$ by weight.

Deagglomeration of fine powders can occur through different mechanisms: erosion of small fragments off the surface of agglomerates, rupture of large agglomerates that result in smaller agglomerates which are broken up further or through the shattering of an agglomerate into its finest fragments in a single event. The process can be monitored by particle size measurements and careful data analysis would indicate the dominant mechanism through of breakup ${ }^{(4,5)}$, providing useful input in equipment choice/process design ${ }^{(6)}$. Such measurements also indicate how fine a dispersion can be achieved. Whilst the mechanism of deagglomeration and dispersion fineness are primarily defined by the particular formulation, i.e. regardless of the choice of process equipment or operating conditions, the kinetics of deagglomeration depend on the flow field generated by the specific design and operation of an equipment. In addition to these, dispersion rheology, due to both the addition of powder and deagglomeration or delamination in the case of nanoclays can play an important role.

Knowledge from such studies has proven to be useful in process design and scale up, both of which are challenging tasks, especially considering the different devices available on the market ${ }^{(7,8)}$ and the need to use different types of equipment from formulation to manufacturing scale. There has been significant progress made in the area with both experimental studies and numerical modelling. Further work continues and the author is keen to establish collaborations.

(1) Etchells, A.W., 2001. "Mixing of floating solids" Plenary lecture ISMIP4, 14-16 May 2001, Toulouse, France

(2) Özcan-Taşkin, N.G. (2013) "Incorporation of nanoparticle clusters into liquids using a proprietary design mixer- Ytron Y Jet: particle concentration, addition method, power input, liquid height and scale" Chem Eng Res Des. (DOI: 10.1016/j.cherd.2013.03.019)

(3) Bacon, J.C.; Rielly, C.D. (2020) "The incorporation of fine powders into a liquid using an in-line rotor-stator"AIChE Fall Meeting

(4) Özcan-Taşkin, N. G.; Padron, G. and Voelkel, A. (2009) "Effect of particle type on the mechanisms of breakup of nanoscale particle clusters" Chem. Eng. Res. Des., 87, No.4, p: 468-473. Doi: 10.1016/j.cherd.2008.12.012

(5) Özcan-Taşkin, N.G (2015) "Dispersion of fine powders in liquids- particle incorporation and size reduction" Pharmaceutical Blending and Mixing, Editors: Cullen, P.J.; Romanach, R.J.; Abatzoglou, N.; Rielly, C.D. Wiley DOI:10.1002/9781118682692

(6) Özcan-Taşkin, N. G.; Padron, G. A.; Kubicki, D. (2016) "Comparative Performance of In-Line Rotor-Stators for Deagglomeration Processes" Chem. Eng. Sci.156 p:186-196. doi.org/10.1016/j.ces.2016.09.023

(7) Özcan-Taşkin, N.G.; Gavi, E.; Kubicki, D.; Wang Y. (2012) "Dispersion of nanoscale silica particles using a novel design stirred bead mill" 14th European Conference on Mixing,10-13 September, Warsaw, Poland.

(8) Gavi, E., Kubicki, D., Padron, G.A., Özcan-Taşkın, N.G. (2018) "Breakup of nanoparticle clusters using Microfluidizer M110P" Chem Eng Res Des, Volume 132, p: 902-912; https://doi.org/10.1016/j.cherd.2018.01.011 